\title{
TSA: An Expert System for Solid Waste Transfer Station
}

\author{
Latifah Abd Manaf (Corresponding author) \\ Department of Environmental Sciences \\ Faculty of Environmental Studies \\ Universiti Putra Malaysia \\ 43400 UPM Serdang \\ Selangor, MALAYSIA
}

Tel: 60-3-8946-6747Ｅ-mail: latifah@env.upm.edu.my

\author{
Goh Pei Pei, Nur Ilyana Mohd Zukki \& Mohd Armi Abu Samah \\ Department of Environmental Sciences \\ Faculty of Environmental Studies \\ Universiti Putra Malaysia \\ 43400 UPM Serdang \\ Selangor, MALAYSIA
}

\begin{abstract}
This paper presents the development of expert system to assist in the operation of solid waste transfer station. The knowledge based consists of a rule-based expert system for the diagnosis of site selection and problems of transfer station and subsequent identification of remedial control actions. Siting criteria are used to identifying and evaluating potential development sites. It is generally recognized that an expert system can cope with many of the common problems relative with the operation and site selection of solid waste transfer station. In this work an expert system is developed which supervises the site selection and problem of waste transfer station. The knowledge acquisition to develop this expert system involved an exhaustive literature review on waste transfer station operation plant and interviews with experienced plant operators. The development tool for this system is Kappa-PC.
\end{abstract}

Keywords: Expert systems, Knowledge acquisition, Solid waste transfer station

\section{Introduction}

Solid waste is a very general term which encompasses all waste materials except hazardous waste, liquid waste, and atmospheric emissions, although "most solid waste regulations include hazardous waste within the definition of solid waste" (Liu et al., 1997). Solid wastes are divided into three main categories: municipal, industrial, and agricultural. Municipal solid waste has several sources such as residential, commercial, institutional, construction and demolition, and municipal services (Tchobanoglous et al., 1993). In general, the amount of solid waste has been increasing in urban areas. The more urbanized the area is the higher amount of per capita waste generation.

A solid waste management system consists of prepared plans and plants that are built for final disposal of waste as well as recycling, reuse, composting, and incineration (Liu et al., 1997). The municipal solid waste management system deals with the municipal solid waste from its source of generation until its final disposal, which includes all the operations and transformation of this waste.

Transfer station is one of the elements in solid waste management system. It plays an important role in a community's total waste management system, serving as the link between a community's solid waste collection program and a final waste disposal facility. (Tzipi et al., 2007) While facility ownership, sizes, and services offered vary significantly among transfer station, they all serve the same basic purpose which is consolidating waste from multiple collection vehicles into larger, high-volume transfer vehicles for more economical shipment to distant disposal sites (US EPA, 2001).

The objective of the research is to develop an expert system for solid waste transfer station. It also expected can overcome most of the problems encountered in solid waste transfer station plant. 


\subsection{The Solid Waste Transfer Station}

Transfer stations are an integral part of present-day in municipal solid waste management systems. The main criteria used to decide on the location of a transfer station has traditionally been the minimization of transport costs, since it is cheaper to transport great amounts of waste over long distances in large loads than in small ones (Bovea et al., 2007) Where the distance from the waste collection area to the waste treatment facility is large, a transfer station may be used to bulk up the waste for more efficient transport by a larger truck (Bovea et al., 2007).

According to Gil \& Kellerman (1989), there are three reasons why transfer stations are useful. First, because small or medium sized communities may not generate sufficient waste to support a disposal facility. Second, if the distance to the disposal plant is long the use of small collection trucks may be unnecessarily high. Third, the location of a single disposal plant in a remote location to serve several communities will remove negative environmental impacts from residential areas.

The main criteria used to decide the feasibility of incorporating a transfer station into a waste management system has traditionally been the minimization of the economic costs of transport to and from the station, since it is cheaper to transport large amounts of waste over long distances in large loads than in small ones (Tchobanoglous et al., 1993). In its simplest form, a transfer station is a facility with a designated receiving area where waste collection vehicles discharge their loads. The waste is often compacted then loaded into larger vehicles for long haul shipment to a final disposal site usually a landfill (USEPA, 2001).

\section{Expert System for Solid Waste Transfer Station}

An expert system is a computer system that attempts to replicate specific human expert intelligent activities. Typically, expert systems enable users with a problem to consult a computer system as they would an expert advisor to diagnose what may be causing a problem and figure out how to solve a problem, perform a task, or make a decision. (Mockler \& Dologite, 1992).

Expert systems are designed to solve real problems in solid waste transfer station which normally would require a specialized human expert to handle. Therefore, building of an expert system involves extracting the relevant knowledge from the human expert. Extracting heuristic knowledge from the expert in a way that can be used by a computer is generally a difficult task, requiring its own expertise. This knowledge extracting and expert system development was done by a knowledge engineer.

According to James (1990), expert systems have a number of distinct advantages as well as disadvantages when compared to other solution such as conventional software or human problem solvers. It can be beneficial for organizations that have clear objectives, rules and procedures. Expert systems can (James 1990): (1) Provide consistent answers for repetitive decisions, processes and tasks. (2) Hold and maintain significant levels of information. (3) Reduce employee training costs. (4) Centralize the decision making process. (5) Create efficiencies and reduce time needed to solve problems. (6) Combine multiple human expert intelligences. (7) Reduce the amount of human errors. (8) Give strategic and comparative advantages creating entry barriers to competitors. (9) Review transactions that human experts may overlook

Although significantly advantageous to many entities, limitations of expert systems may arise through (James 1990): (1) The lack of human common sense needed in some decision makings. (2) The creative responses human experts can respond to in unusual circumstances. (3) Domain experts not always being able to explain their logic and reasoning. (4) The challenges of automating complex processes. (5) The lack of flexibility and ability to adapt to changing environments. (6) Not being able to recognize when no answer is available.

\section{Methodology}

\subsection{Components of Expert System}

There are three basic components in expert system which are a knowledge base, a user interface and an inference engine (Jayawardhana et al., 2003). The knowledge base contains knowledge necessary for understanding, formulating and solving problems. It includes two basic elements: (1) facts in its various states, and (2) rules that direct the use of knowledge to solve specific problems in particular domain. Modification of knowledge base is important in most engineering domains, since knowledge is continually changing and expanding.

The user interface is the part of the program that controls the conservation between user and computer. User interfaces can be defined as the point where users interact with a computer system (Mockler \& Dologite, 1992). The user interface determines whether the conversation consists of selecting items from menus, responding yes or no to question or filling in forms. The user interface is also responsible for the degree to which the system can explain its solution otherwise assist users (Meng \& Frederick 1996). The inference engine is the heart of the expert system since this is the part of the program that builds the bridge between information and solutions. 
According to James (1990), generally the stages of expert system development are: (1) Task analysis. The first stage of developing an expert system involved analysis of the tasks with the main objective was to identify and understand the problem to be solved. The scope of domain in this research is solid waste transfer station which consist tasks and subtasks as shown in Table 1. The tasks involved in waste transfer station are types of waste accepted, siting criteria, design of transfer station, and benefit of transfer station, problems and operations of transfer station. (2) Knowledge acquisition. Knowledge acquisition is the knowledge engineering job of acquiring and organizing the knowledge needed to develop an expert system. It involves organizing and representing the knowledge in a way that ensures an accurate replication of the knowledge and the decision situation in a form useful for transferring to a computer system. There are two stages of knowledge acquisition in this research. The first stage involved a knowledge acquisition from written sources. Table 2 shows a list of textual sources used to acquire the knowledge for the prototype. The second stage involved interacting with domain experts through unstructured interview and observation in the field. (3) Prototype development. In this stage, knowledge expertise will be transform into computer programmed. In developing prototypes, an effort is made to select only the most critical factors and show only their most basic relationship, in order to test the underlying structure and concept of the system. Rules are written for the knowledge base in this development stage. IF-THEN rules are the common way to represent knowledge in current expert systems. The rule contain premises or conditions in the IF clauses, and conclusions in the THEN clauses. IF-THEN rules in expert systems can be modified easily to meet changing needs. Hence, it was easy to update. It also has the capability to ask users questions about information needed to deal with specific problems during consultations. (4) Expansion and refinement. This stage required the expert to add more knowledge expertise into the knowledge base of the prototype. The prototype reviewed repeatedly and rapidly until a sufficiently satisfactory prototype is achieved. (5) Verification and validation. An important step of an expert system development process is the evaluation of the performance of the systems, which involves both verification and validation. It is very important that expert systems are verified and validated before their effective employment in the intended user environment. In consultation process, the performance of the system must be similar to the expert's prediction.

\subsection{Development Tools}

Expert system can be developed by using conventional programming and expert system shell. Expert system shells contain such components as inference engine programs, programmed control mechanisms for managing the knowledge base, facilities for explaining how and why conclusion was reached, and capabilities for storing and editing knowledge bases. For these reasons, expert system shells can be easier and quicker to use than programming language. The example of expert system shells are ESIE, VP-Expert and JAVA. For this research, Kappa-PC was selected as a development tool because it is suitable to be use in limited time and has substantial object capabilities.

\section{Result and Discussion}

The expert system in this research is called Transfer Station Advisor (TSA). The architecture of TSA is shown in Figure 1. The knowledge base of TSA consists of six modules: (1) types of waste accepted, (2) siting criteria, (3) transfer station design, (4) transfer station operations, and (5) problems of transfer station, as shown in the main interface (Figure 2). Below are discussions of main modules in TSA.

\subsection{Types of waste accepted module}

Some transfer stations also offer programs that manage specific materials separately to divert waste from disposal and to achieve recycling objectives. These materials could include construction and demolition debris, yard waste, household hazardous waste, or recyclables. The types of materials processed often vary depending on where the facility is located (urban, suburban, rural) and who owns and operates the operation at the transfer station. The types of waste that are commonly handled at transfer stations are municipal solid waste (MSW), residential, commercial, and construction and demolition.

\subsection{Siting Criteria Module}

Identifying a suitable site for establishment of a waste transfer station can be challenging. It is therefore useful to undertake a transparent site selection process to determine an appropriate site for development. This module has three components which consist of environmental, technical as well as community and social siting criteria. Under each components still have theirs subcomponents for user guideline and problem solver that user will face during site selection. Figure 3 shows user the main interface of the siting criteria. In order to locate transfer station, technical and environmental aspects must be considered.

\subsubsection{Technical siting criteria sub-module}

This sub-module provides specific engineering, operation and transportation conditions that should be taken into account to ensure that potential sites are suitable to build up a transfer station. For example: central location to collection routes. As a rule of thumb in urban area, transfer station should be less than $2 \mathrm{~km}$ away from the end of all collection routes. This is because the aim we build transfer station is to save money and transportation fuel. If we 
broken this rule, the objective for build a transfer station for community cannot be achieve. Figure 4 show that the components in technical siting criteria interface.

\subsubsection{Environmental siting criteria sub-module}

Land use, geology, groundwater, surface water, ecology, visibility, traffic and topography are important in environmental siting criteria. This sub-module gives guidance to the user on how to reduce environmental impacts during the development of transfer station (Figure 5). As a result, site topography should be taken into consideration to reduce the prevalence of potential wind blown litter and to minimize the number of vantage points that the site is visible from (US EPA, 2001). The impact of site topography on construction requirements should also carefully considered because a transfer station with well equipped will reduce the amount of excavation works and additional fell requirements (US EPA, 2001).

\subsubsection{Community and social sub-module}

The third category of criteria to consider is impact that the facility will have on the surrounding community. These criteria are typically less technical in nature and incorporate local, social, and cultural factors. Examples of these criteria include environmental justice considerations (e.g.: clustering, cumulative impacts), impact on air quality, impact on the local infrastructure, proximity to schools, churches, recreation sites, and residences, number of residences impacted, impact on historic or cultural features, impact on neighborhood character and impacts on existing businesses.

\subsection{Design of Transfer Station Module}

Most activities at a transfer station occur within the main transfer building. A good site layout will ensure the operations of transfer station are more efficient. Two other factors should be considered were vehicles and technology used by the transfer station.

Site layout of the transfer station must include road entrances and exits, traffic flow routes on site, queuing areas, reception area, buildings, fence and gate, weighing bridge, holding area, unloading platforms and buffer areas. Lack of one component will cause the functions of the transfer station are not efficient. Figure 6 shows the layout of transfer station.

\subsection{Transfer Station Operation Module}

Although the basic function of a transfer station as a waste consolidation and transfer facility is straightforward, operating a successful station involves properly executing many different tasks. Some tasks are routine and easily understood, while others occur infrequently and might be difficult to conduct properly without step-by-step directions. This module provides guideline to the users that can assist in operating transfer station successfully which consist of operations and maintenance plans, facility operating hours, interacting with the public, waste screening, emergency situations, record keeping and guideline for emergency events.

\subsection{Problem of Transfer Station Module}

Traffic, noise and odor may exist around solid waste transfer station. Beside that, improper designed or operated of transfer station may cause air emissions, vectors and litter. A good design and positioning of transfer station can reduce all the problems significantly. This module provides possible solutions to overcome most of the problems encountered at the transfer stations.

\subsection{IF-THEN Rules}

The example of rules developed in TSA is described briefly in this section. Figure 7 show rules for emergency situation. If power failure occurs at transfer station, then the operator should have backup power generations so at least some operations can continue during power failure.

Other rule is injuries to employee which can effect the operation of station. If it happened, operator should have first aid procedures, emergency phone numbers and routes to nearby hospitals.

\subsection{Case Study}

The most challenging part of building an expert system is testing. The basic motivation behind testing is to control performance, efficiency and quality of the knowledge base. The goal is compliance with user expectations and system functioning. Validation of an expert system means to make certain that the advice given by the system will be valid in all of its applications. As a summary, TSA must act like a human expert.

In order to validate and verify the TSA, a case study has been carried out at Ampang Jajar Transfer Station situated at Seberang Perai, Pulau Pinang. The operation of this transfer station was started in 2002 and it using a vertical compactor system. Data such as generation rate, types of waste accepted, hauling distance, and disposal area are collected. From the collected data, this transfer station handled 350 tons of domestic and garden waste per day and 
disposed at Pulau Burung Landfill. A validation has been carried out using those data and the final conclusion of the system was expected and consistent with the predictions of the domain expert.

\subsection{End users}

Persons who involved with transfer station operation and solid waste management are targeted end users of TSA. Typically, supervisors of transfer station are responsible for the operation of transfer station. Thus, the TSA expectantly can help them to make a quick solution of the problems encountered during the operation. The user-friendly characteristics of TSA make the system easily to use without any knowledge in computer programmed.

\section{Conclusions}

TSA is developed for the diagnosis of solid waste transfer station by using Kappa-PC shell. Hopefully, the prototype can overcome most of the problems encountered in transfer station design and operation. The knowledge base of TSA consists of expertise which is acquired from multiple sources. A secondary data are collected in order to verify and validate the prototype. As conclusion, expertise in TSA was expected and consistent with the predictions of the human expert.

\section{ACKNOWLEDGEMENTS}

We would like to express our appreciation to the experts from Ampang Jajar Waste Transfer Station and Pulau Pinang Waste Transfer Station for their willingness to spare their time for the interview sessions and site visits.

\section{References}

Agamuthu, P. 2001. Solid Waste: Principles and Management. Institute of Biological Sciences, University of Malaya Kuala Lumpur, Malaysia.

Bovea, M.D., Powell, J.C., Gallardo, A. \& Capuz-Rizo S.F. 2007. The role played by environmental factors in the integration of a transfer station in a municipal solid waste management system. Waste Management 27(4): 545-553.

Department of Environment and Conservation, NSW. 2006. Handbook for Design and Operation of Rural and Regional Transfer Station.

Gil, Y. \& Kellerman, A. 1989. A multicriteria model for the location of solid waste transfer stations: the case of Ashdod, Israel, Mimeo, Department of Geography, University of Haifa.

James, P.I. 1990. A brief introduction to expert systems. Computers \& Operations Research. 17(6):523-533.

Jayawardhana, L.C., Aruna Manipura, Ajith De Alwis, Malik Ranasinghe, Sumith Pilapitiya \& Indrika Abeygunawardena. 2003. BESTCOMP: Expert system for Sri Lankan solid waste composting .Expert Systems with Applications 24(3): 281-286.

Liu, D.H., Liptak, B.G. \& Bouis, P.A. 1997. Environmental Engineers Handbook, second ed. Lewis Publishers, New York.

Meng, S.W. \& Frederick, W. 1996. An Expert System for Waste Management. Journal of Environmental Management 46(4): 345-358.

Mockler, J. \& Dologite, D.G. 1992. Knowledge-Based System: An Introduction to Expert Systems. Mcmillan, New York.

Tchobanoglous, G., Theisen, H. \& Vigil, S. 1993. Integrated Solid Waste Management. McGraw-Hill, New York.

Tzipi, E., Mira G.B., Mordechai, S. \& Ofira, A. 2007. Measuring externalities of waste transfer stations in Israel using hedonic pricing. Waste Management 27(5): 614-625.

US EPA. 2000.Waste Transfer Stations: Involved Citizens Make the Difference. EPA530-K-01-003. Office of Solid Waste and Emergency Response, Washington.

US EPA. 2001.Waste Transfer Stations: A Manual for Decision Making. EPA530-K-01-005. Office of Solid Waste and Emergency Response, Washington. 
Table 1. Task analysis in Transfer Station Advisor

\begin{tabular}{|c|c|}
\hline Module & Function \\
\hline Types of waste accepted & $\begin{array}{l}\text { Module supervising the types of waste commonly handled } \\
\text { at transfer stations and specific materials separately manage } \\
\text { by transfer station. }\end{array}$ \\
\hline Siting criteria & $\begin{array}{l}\text { Module supervising the criteria for identifying a suitable } \\
\text { site for waste transfer station depends on technical, } \\
\text { environmental and community criteria. }\end{array}$ \\
\hline Transfer station design & $\begin{array}{l}\text { Module supervising the layout of the transfer station site's } \\
\text { major features and vehicle and technology that use by a } \\
\text { waste transfer station. }\end{array}$ \\
\hline Benefit of transfer station & $\begin{array}{l}\text { Module supervises the benefit of building a waste transfer } \\
\text { station at our waste management. }\end{array}$ \\
\hline Transfer station operations & $\begin{array}{l}\text { Module supervising the operations issues and suggests } \\
\text { operational practices intended to minimize the facility's } \\
\text { impact on the community. }\end{array}$ \\
\hline Problems & $\begin{array}{l}\text { Module supervising the problem that may exist around } \\
\text { waste transfer station and also the matter of solving the } \\
\text { problem. }\end{array}$ \\
\hline
\end{tabular}

Table 2. Source of knowledge base

\begin{tabular}{|c|c|c|c|}
\hline Author & Year & Title & Publisher \\
\hline Agamuthu, $\mathrm{P}$ & 2001 & $\begin{array}{l}\text { Solid Waste: Principles } \\
\text { and Management. }\end{array}$ & $\begin{array}{l}\text { Institute of Biological } \\
\text { Sciences, University of } \\
\text { Malaya, Malaysia. }\end{array}$ \\
\hline $\begin{array}{l}\text { Department of } \\
\text { Environment and } \\
\text { Conservation NSW }\end{array}$ & 2006 & $\begin{array}{l}\text { Handbook for Design and } \\
\text { Operation of Rural and } \\
\text { Regional Transfer Stations }\end{array}$ & $\begin{array}{l}\text { Department of } \\
\text { Environment and } \\
\text { Conservation NSW }\end{array}$ \\
\hline $\begin{array}{l}\text { Mockler, J. \& Dologite, } \\
\text { D.G. }\end{array}$ & 1992 & $\begin{array}{l}\text { Knowledge-based system: an } \\
\text { introduction to expert systems. }\end{array}$ & Mcmillan, New York. \\
\hline $\begin{array}{l}\text { Tchobanoglous, G., } \\
\text { Theisen, H. \& Vigil, S. }\end{array}$ & 1993 & $\begin{array}{l}\text { Integrated Solid Waste } \\
\text { Management. }\end{array}$ & McGraw-Hill, New York \\
\hline USEPA, & 2001 & $\begin{array}{l}\text { Waste Transfer Stations: A } \\
\text { Manual for Decision-Making }\end{array}$ & EPA(530-D-01-005) \\
\hline USEPA & 2000 & $\begin{array}{l}\text { Involved Citizens Make the } \\
\text { Difference }\end{array}$ & EPA(530-K-01-003) \\
\hline
\end{tabular}




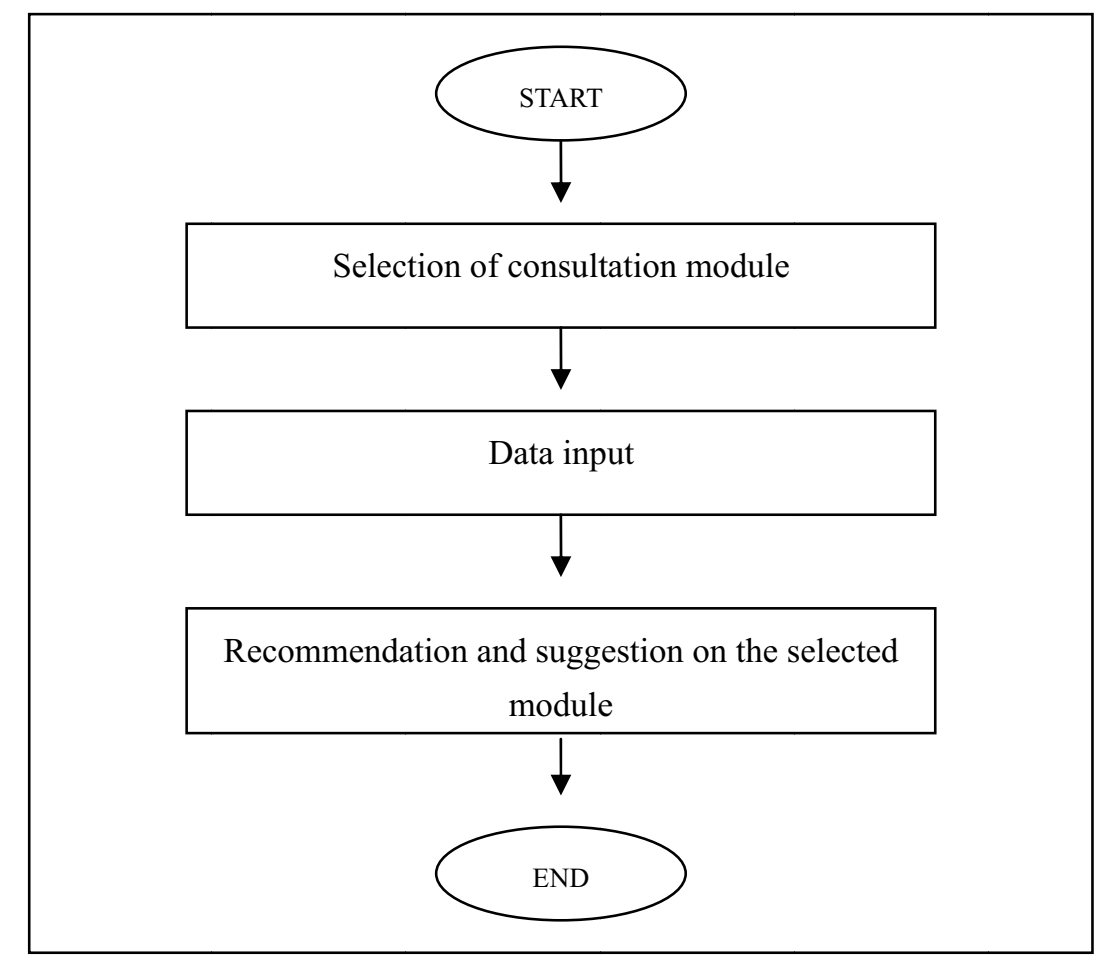

Figure 1. Architecture system of TSA

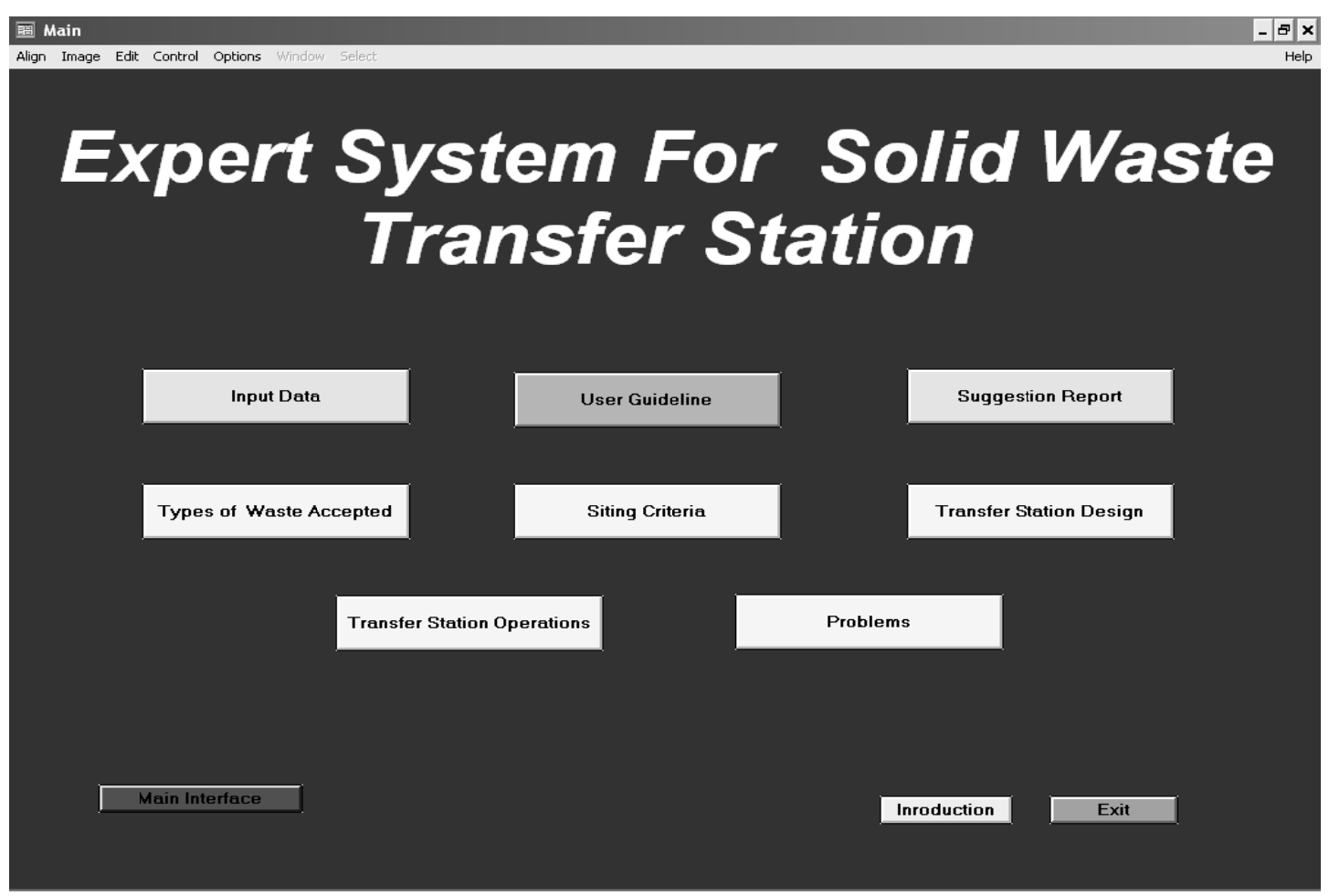

Figure 2. The main interface of TSA 


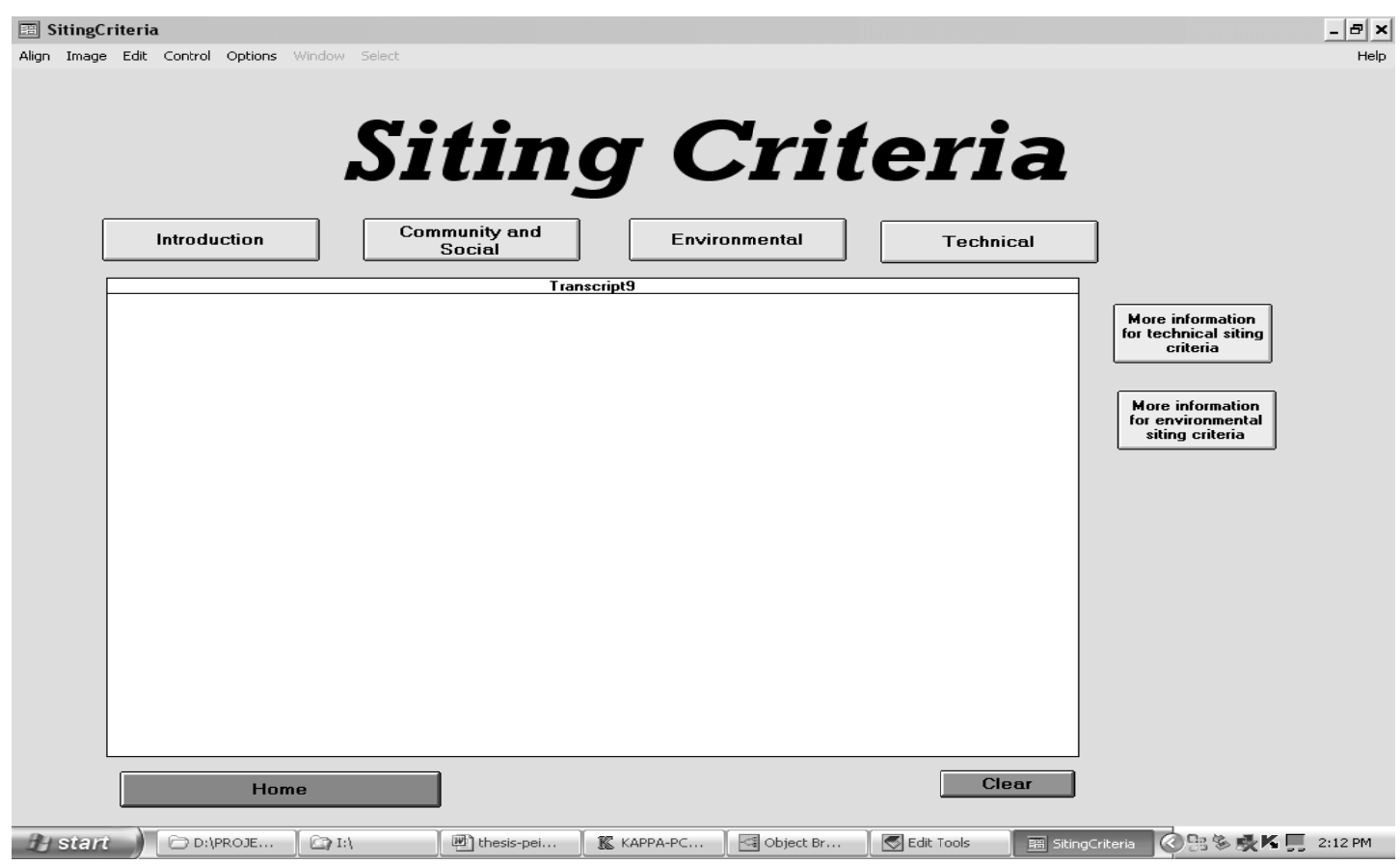

Figure 3. The main interface in siting criteria module

\section{Technical Siting Criteria}

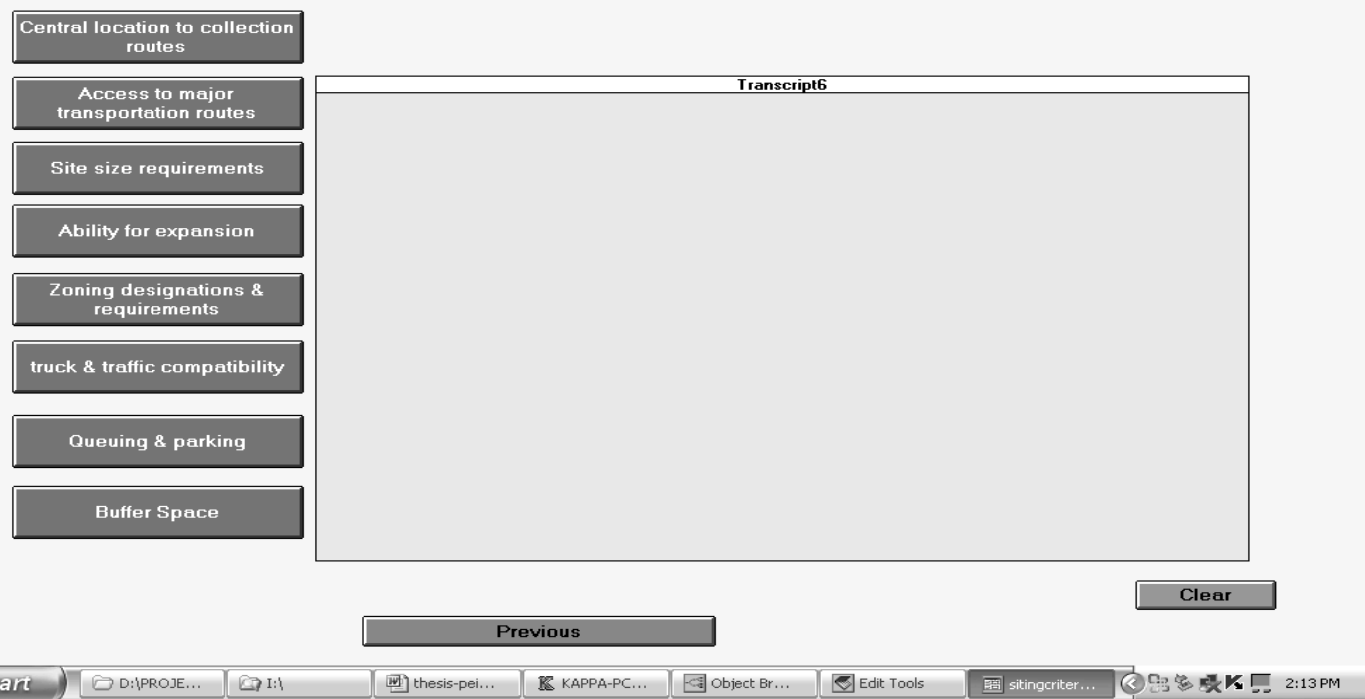

Figure 4. The technical siting criteria interface in TSA 


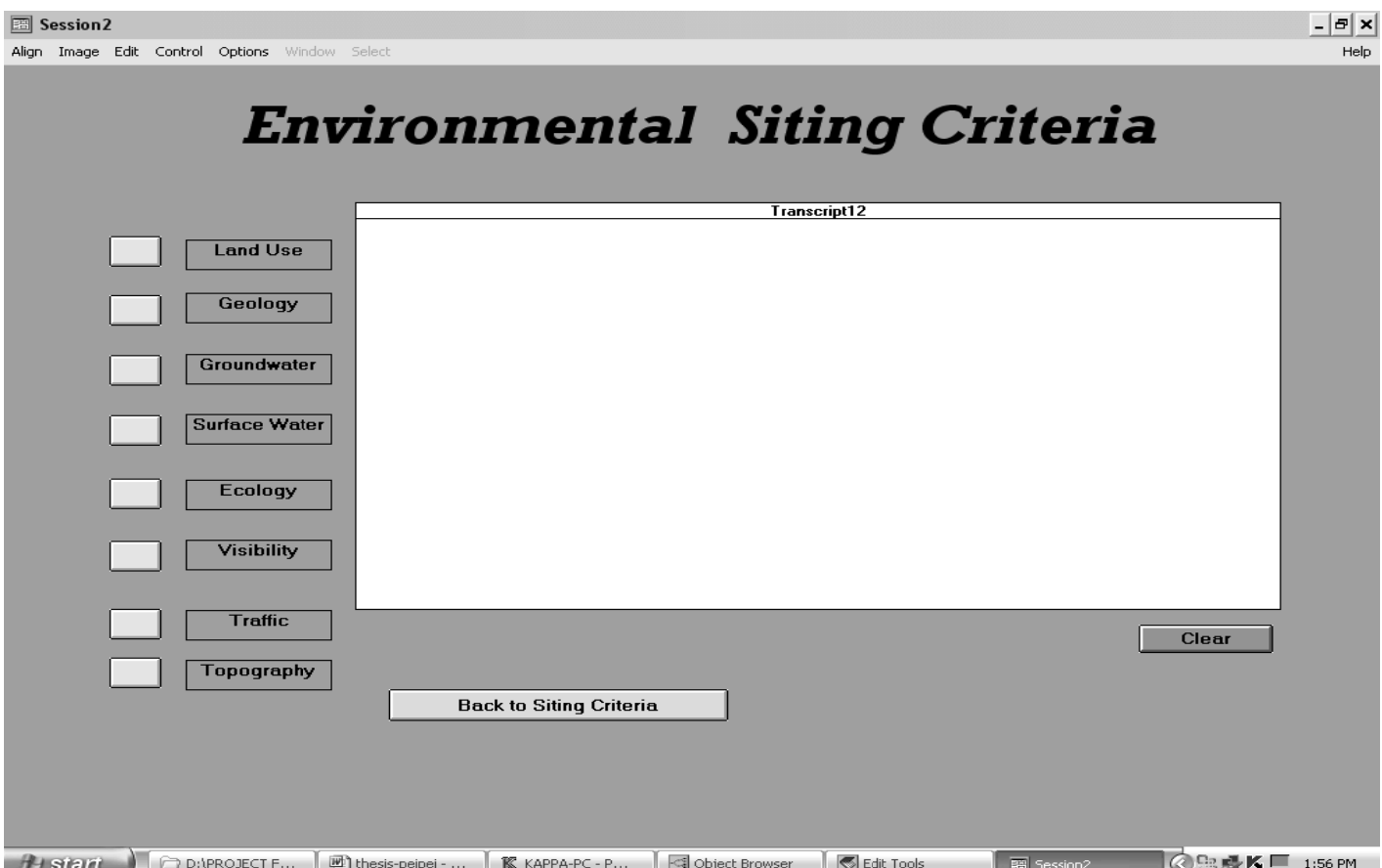

Figure 5. The environmental siting criteria interface of TSA

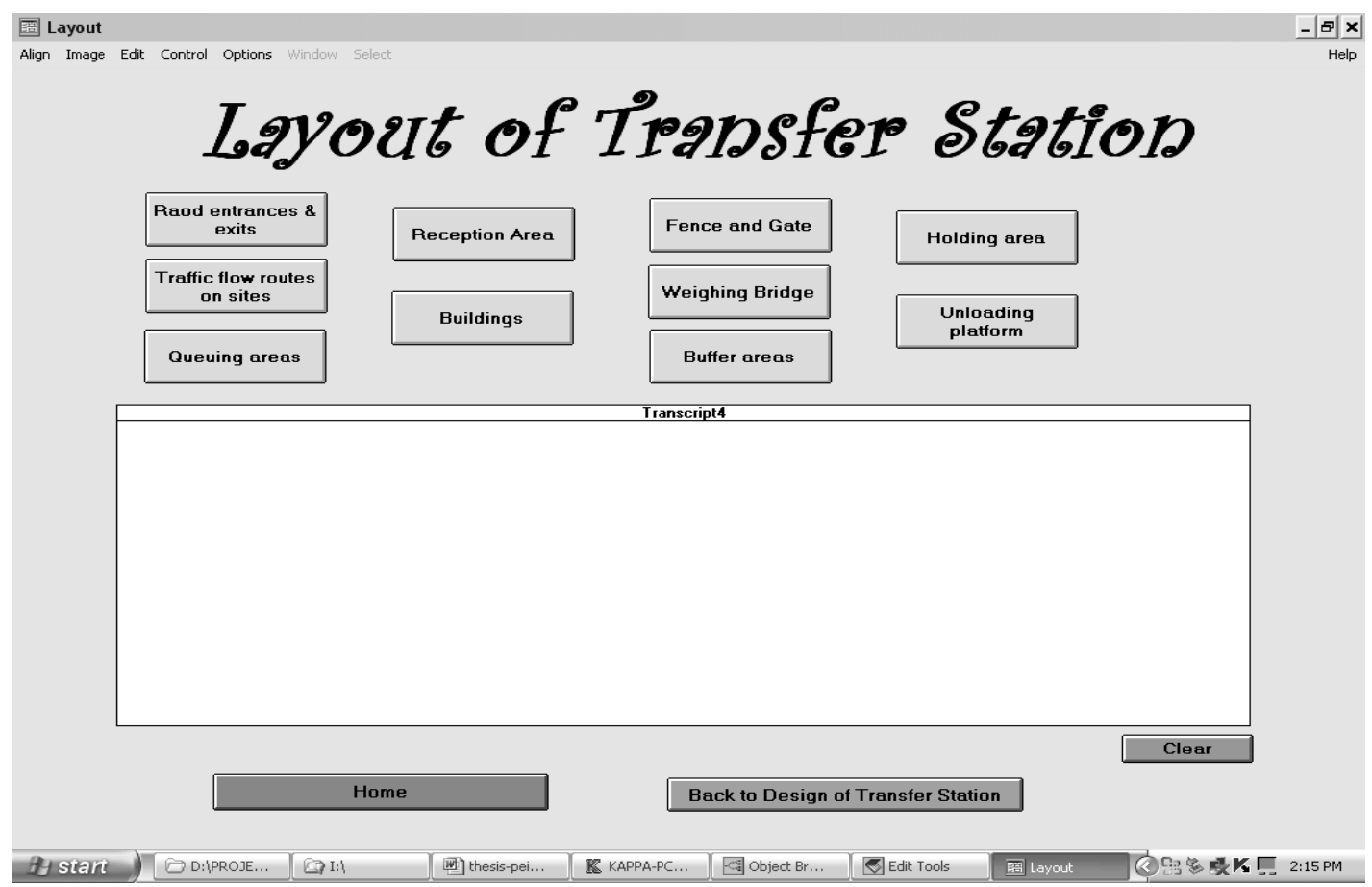

Figure 6. The layout of transfer station interface of TSA 
RULE Emergency

IF Emergency: PF = TRUE;

THEN Backup power generations so at least some operations can continue when power failure.

RULE Emergency

IF Emergency: INJURIES = TRUE;

Figure 7. Examples of IF-THEN rules 